\title{
Dialysis Surveillance Report: National Healthcare Safety Network (NHSN)-Data Summary for 2006
}

\author{
R. Monina Klevens, Jonathan R. Edwards, Mary L. Andrus, Kelly D. Peterson, Margaret A. \\ Dudeck, Teresa C. Horan, and the NHSN Participants in Outpatient Dialysis Surveillance \\ Division of Healthcare Quality Promotion, National Center for Preparedness, Detection and Control of \\ Infectious Diseases, Centers for Disease Control and Prevention, Public Health Service, U.S. Department of \\ Health and Human Services, Atlanta, Georgia
}

\begin{abstract}
Thirty-two outpatient hemodialysis providers in the United States voluntarily reported 3699 adverse events to the Centers for Disease Control and Prevention (CDC) National Healthcare Safety Network (NHSN) during 2006. These providers were previously enrolled in the Dialysis Surveillance Network. The pooled mean rates of hospitalization among patients with arteriovenous fistulas, grafts, permanent and temporary central venous catheters were 7.7, 9.2, 15.7, and 34.7 per 100 patient-months, respectively. For bloodstream infection the pooled mean rates were $0.5,0.9,4.2$, and 27.1 per 100
\end{abstract}

patient-months in these groups. Among the 599 isolates reported, $461(77 \%)$ represented access-associated blood stream infections in patients with central lines, and $138(23 \%)$ were in patients with fistulas or grafts. The microorganisms most frequently identified were common skin contaminants (e.g., coagulase-negative staphylococci). In 2007, enrollment in NHSN opened to all providers of outpatient hemodialysis. Specific information is available at http://www.cdc.gov/ ncidod/dhqp/nhsn_FAQenrollment.html.

\section{Background}

In the United States, 309, 269 people were treated for end-stage renal disease (ESRD) by hemodialysis during 2004 (1). This number of cases was a record high and almost twice the number treated just 10 years earlier (1). Infections are the second most common cause of death among ESRD patients, and they account for nearly $14 \%$ of deaths (1). Their risk of infection occurs as a result of immunosuppression and is exacerbated by the need to routinely access their bloodstream for treatment. Antimicrobial resistance is of particular concern because hemodialysis patients are often hospitalized, where they can be exposed to antibiotic-resistant pathogens. In addition, they are often treated with long courses of antimicrobials (2).

The National Kidney Foundation's Kidney Disease Outcome Quality Initiative (DOQI) guidelines recommend monitoring vascular infections to identify outbreaks and observe trends (3). CDC guidelines to prevent intravascular catheter-related infections recommend surveillance of catheter insertion, maintenance and infection rates (4). Local (i.e., center-specific) surveillance

Address correspondence to: R. Monina Klevens, Division of Healthcare Quality Promotion, Centers for Disease Control and Prevention, 1600 Clifton Rd. (A-24), Atlanta, GA 30333, ore-mail: rmk2@cdc.gov.

Seminars in Dialysis-Vol 21, No 1 (January-February) 2008 pp. 24-28

DOI: $10.1111 /$ j. 1525-139X.2007.00379.x of infections can help identify areas where improvements in infection control might be necessary. Additionally, local surveillance data can be used to evaluate the effectiveness of prevention interventions. If providers are to prevent antimicrobial resistance, monitoring antimicrobial use and antimicrobial resistance of organisms associated with infections in dialysis patients is critical (5).

\section{Methods}

CDC's National Healthcare Safety Network (NHSN) is the successor system to the Dialysis Surveillance Network (DSN; 6), the National Nosocomial Infections Surveillance System (NNIS; 7), and the National Surveillance System for Healthcare Workers. During 2005, outpatient hemodialysis providers already in the Dialysis Surveillance Network transitioned into the NHSN. Dialysis surveillance activities are part of the NHSN Patient Safety Component, Device-Associated Module. The detailed protocol and case report forms are available at http://www.cdc.gov/ncidod/dhqp/nhsn_members.html. Participants include free-standing and hospital-based centers that provide outpatient, chronic hemodialysis.

At each participating dialysis center, staff members monitor patients for any of three specific events that trigger a report: (1) an overnight hospital stay, (2) an outpatient start of an intravenous (IV) antimicrobial, or (3) a positive blood culture. More than one specific event 
may be recorded on the same patient's report. After 20 days, the occurrence of an outpatient start of an IV antimicrobial or a positive blood culture in a patient is considered a new case; a new hospitalization can be reported at any time. The case report form captures basic clinical data for each patient and event, including the type of vascular access and use of vancomycin. Information used to estimate the denominator (patientmonths) is obtained during the first two working days of the month. During those 2 days, the number of patients with each type of vascular access is recorded (fistula, graft, temporary and permanent central line, and port). Rates expressed in patient-months can be interpreted as the average percentage of patients having the event each month (8).

Dialysis staff members enter this information monthly using NHSN's reporting tool, accessible through CDC's Secure Data Network. Center-specific data are immediately available on-line. Data aggregated from all centers are analyzed at CDC. Patient and center information is protected at CDC by provisions of federal Public Health Service law (9).

\section{Definitions}

Each center determined whether a central line used for vascular access was considered temporary or permanent. A port vascular access was a fully implantable access device (e.g., Lifesite). We defined a hospitalization as any report where a patient stayed overnight in a hospital, regardless of cause. An antimicrobial start was any initiation of a new antimicrobial agent not in use for the previous 21 days, and delivered IV. Vancomycin starts were a subset of antimicrobial starts for which vancomycin was the agent used. We defined a local access infection as the presence of pus, redness, or swelling of the vascular access site without access-associated bloodstream infection. An access-associated bloodstream infection was defined as a patient with a microorganism identified in a blood culture where the source of infection was the vascular access site. A bloodstream infection was a report of a positive blood culture, regardless of the source of the infection, and included access-associated bloodstream infections. A vascular access infection was a patient with either a local access infection or an access-associated bloodstream infection.

In this report, we summarize data submitted by hemodialysis centers to the NHSN during 2006.

\section{Results}

Thirty-two centers providing outpatient hemodialysis reported data to the NHSN in 2006. These centers submitted data on 28,047 patient-months: 12,140 (43\%) were among patients with fistulas, $8806(31 \%)$ with permanent central lines, 6907 (25\%) with grafts, $118(0.4 \%)$ with temporary central lines, and $76(0.3 \%)$ with ports. During 2006, dialysis centers reported 3699 adverse events. The number of events reported among patients with ports was not adequate to calculate rates or rate dis- tributions. The number of events reported among patients with temporary central lines was not adequate to provide distribution of rates. Event rates varied by vascular access type (Table 1). The most frequent event was hospitalization (2985 reports). The pooled mean rate of hospitalization ranged from 7.7 per 100 patientmonths among patients with fistulas to 34.7 per 100 patient-months among patients with temporary central lines. Percentiles describing the variability of rates across participating dialysis centers are also shown in Table 1. Half of the centers had a rate of hospitalization $\geq 7.9$ per 100 patient-months among patients with fistulas.

The pooled mean rate among the 977 reports of antimicrobial starts ranged from 1.8 to 25.4 per 100 patientmonths. In $73 \%$ of these events, vancomycin was used; the pooled mean rate of vancomycin starts ranged from 1.2 to 16.1 per 100 patient-months. The pooled mean rate of bloodstream infection ranged from 0.5 to 27.1 per 100 patient-months. The pooled mean rate of a vascular access infection (either a local access infection or an access-associated bloodstream infection) ranged from 0.4 to 22.9 per 100 patient-months.

Among the 532 positive blood cultures, 599 isolates were reported. Of these, 461 (77\%) represented accessassociated bloodstream infections in patients with central lines, and $138(23 \%)$ were in patients with fistulas or grafts (Table 2). Among isolates from patients with either a central line, fistula, or graft, the microorganisms most frequently identified were common skin contaminants (e.g., coagulase-negative staphylococci). Overall, 181 isolates from positive blood cultures were tested for antimicrobial susceptibility and results reported to NHSN (Table 3). The most frequently reported organism was $S$. aureus of which $42 \%$ were resistant to methicillin (MRSA). Of the enterococci tested and reported, $26 \%$ were resistant to vancomycin.

\section{Discussion}

In 2006, rates of adverse events were higher among dialysis patients with central lines than among those with fistulas or grafts $(8,10,11)$. The rate of hospitalization among patients with temporary central lines was 34.7 per 100 patient-months, about four times the rate among those with fistulas or graphs (7.7-9.2 patients per 100 patient-months). Likewise, the rate of bloodstream infection was substantially higher among patients with temporary central lines (27.1 per 100 patient-months) than among patients with fistulas or grafts $(<1$ per 100 patient-months). Through the Fistula First Campaign, the Centers for Medicare and Medicaid Services (CMS), ESRD Networks, the renal community, and the Institute for Healthcare Improvement (IHI) are working with many other partners, including $\mathrm{CDC}$, to improve the likelihood that patients receive the most optimal form of vascular access; generally an arteriovenous fistula. Complications related to vascular access are also avoided through appropriate access monitoring and intervention (12). However, even with optimal vascular access, careful attention to infection control is necessary to help prevent infections (13). 
TABLE 1. Pooled means and key percentiles of the distribution of rates of dialysis surveillance events by type of vascular access, device-associated module, patient safety component, National Healthcare Safety Network, 2006

\begin{tabular}{|c|c|c|c|c|c|c|c|}
\hline \multirow[b]{2}{*}{ Type of access } & \multirow[b]{2}{*}{ Event $^{\mathrm{a}}$} & \multicolumn{6}{|c|}{ Percentile } \\
\hline & & $\begin{array}{l}\text { Pooled } \\
\text { mean }\end{array}$ & $10 \%$ & $25 \%$ & $\begin{array}{c}50 \% \\
\text { (median) }\end{array}$ & $75 \%$ & $90 \%$ \\
\hline \multicolumn{8}{|l|}{ Hospitalization } \\
\hline Fistula & 932 & 7.7 & 0.1 & 2.9 & 7.9 & 10.4 & 11.3 \\
\hline Graft & 632 & 9.2 & 0 & 3.6 & 9.8 & 13.2 & 15.1 \\
\hline Perm. central line & 1380 & 15.7 & 0.3 & 9.5 & 15.8 & 21.2 & 25.2 \\
\hline Temp. central line & 41 & 34.7 & - & - & - & - & - \\
\hline \multicolumn{8}{|l|}{ Antibiotic starts } \\
\hline Fistula & 218 & 1.8 & 0 & 0.3 & 1.4 & 2.8 & 3.9 \\
\hline Graft & 163 & 2.4 & 0 & 0.6 & 1.8 & 3.7 & 5.5 \\
\hline Perm. central line & 566 & 6.4 & 0 & 2.2 & 4.8 & 10.5 & 12.8 \\
\hline Temp. central line & 30 & 25.4 & - & - & - & - & - \\
\hline \multicolumn{8}{|l|}{ Vancomycin } \\
\hline Fistula & 148 & 1.2 & 0 & 0 & 1.2 & 2 & 2.7 \\
\hline Graft & 113 & 1.6 & 0 & 0.3 & 1.2 & 2.2 & 4 \\
\hline Perm. central line & 436 & 5.0 & 0 & 1.8 & 3.1 & 7.8 & 9.5 \\
\hline Temp. central line & 19 & 16.1 & - & - & - & - & - \\
\hline \multicolumn{8}{|l|}{ Bloodstream infection } \\
\hline Fistula & 63 & 0.5 & 0 & 0 & 0.3 & 0.7 & 1.1 \\
\hline Graft & 63 & 0.9 & 0 & 0 & 0.6 & 1.6 & 2.2 \\
\hline Perm. central line & 374 & 4.2 & 0 & 1.6 & 3.4 & 6 & 9.4 \\
\hline Temp. central line & 32 & 27.1 & - & - & - & - & - \\
\hline \multicolumn{8}{|l|}{ Local access infection } \\
\hline Fistula & 27 & 0.2 & 0 & 0 & 0 & 0.2 & 1 \\
\hline Graft & 31 & 0.4 & 0 & 0 & 0 & 0.5 & 1.1 \\
\hline Perm. central line & 148 & 1.7 & 0 & 0 & 0.5 & 1.8 & 3.9 \\
\hline Temp. central line & 6 & 5.1 & - & - & - & - & - \\
\hline \multicolumn{8}{|c|}{ Access-associated bloodstream infection } \\
\hline Fistula & 26 & 0.2 & 0 & 0 & 0 & 0.3 & 0.5 \\
\hline Graft & 31 & 0.4 & 0 & 0 & 0.2 & 0.8 & 1.5 \\
\hline Perm. central line & 272 & 3.1 & 0 & 0.6 & 2.4 & 4.5 & 6.3 \\
\hline Temp. central line & 21 & 17.8 & - & - & - & - & - \\
\hline \multicolumn{8}{|c|}{ Vascular-access infection } \\
\hline Fistula & 53 & 0.4 & 0 & 0 & 0.3 & 0.7 & 1.3 \\
\hline Graft & 62 & 0.9 & 0 & 0 & 0.7 & 1.3 & 2.1 \\
\hline Perm. central line & 420 & 4.8 & 0 & 2 & 3.6 & 6 & 10.7 \\
\hline Temp. central line & 27 & 22.9 & - & - & - & - & - \\
\hline
\end{tabular}

Perm, permanent; temp, temporary.

The number of events reported among patients with temporary central lines was not adequate to provide distribution of rates. a Number of patient-months 100 .

Consistent with previous reports $(8,10)$ we found that among bloodstream infections in patients with central lines, the most frequently reported organisms were common skin contaminants. However, among patients with fistulas or grafts, the frequency of common skin contaminants was somewhat higher in 2006 than during 1999-2005 (10). We cannot determine whether any of the common skin contaminants were true pathogens or specimen contamination $(14,15)$. Antimicrobial treatment based on a report reflecting contamination can lead to antimicrobial resistance (see http://www.cdc. gov/drugresistance/healthcare/patients.htm\#dialysis).

Monitoring organisms associated with infections and their resistance patterns is necessary for prevention of resistance (5). Methicillin-resistant Staphylococcus aureus is a major problem among patients on hemodialysis; the rate of invasive MRSA infections in dialysis patients was an estimated 45 per 1000 in 2005 in the United States (16). Among dialysis centers participating in NHSN, $42 \%$ of all $S$. aureus isolates from positive blood cultures were MRSA. To prevent infec- tions with MRSA and other resistant organisms in outpatient dialysis centers a comprehensive approach that includes prevention of infections, judicious antimicrobial use, and prevention of transmission is needed (17).

Participation in NHSN is voluntary, and CDC restricted enrollment during 2006 to existing participants in NNIS or DSN. Therefore, results reported may not represent all U.S. centers providing outpatient hemodialysis. Currently, all U.S. outpatient hemodialysis centers interested in participating in NHSN are invited to enroll. Participating centers can be free-standing dialysis centers or centers affiliated with a hospital, but they should serve mostly ambulatory, chronic hemodialysis patients. To participate in NHSN, centers must meet certain technical requirements (i.e., Internet access, a valid e-mail address, and have the ability to download a digital certificate) and make a commitment to follow the data collection protocol, complete an annual practices survey, and report data for dialysis events and denominator data for at least 6 months in a given year. For 
TABLE 2. Microorganisms isolated from blood cultures reported by U.S. participants in outpatient dialysis surveillance by type of vascular access, device-associated module, patient safety component, National Healthcare Safety Network, 2006

\begin{tabular}{lcc}
\hline & $\begin{array}{c}\text { Central } \\
\text { line-associated } \\
\text { bloodstream } \\
\text { infection } \\
\text { number }(\%)\end{array}$ & $\begin{array}{c}\text { Fistula or graft } \\
\text { access-associated } \\
\text { bloodstream } \\
\text { infection } \\
\text { number }(\%)\end{array}$ \\
\hline $\begin{array}{l}\text { Staphylococcus aureus } \\
\text { Other gram-positive }\end{array}$ & $91(19.7)$ & $39(28.3)$ \\
Gram-negative rods & $46(10.0)$ & $22(15.9)$ \\
Common skin & $107(23.2)$ & $19(13.8)$ \\
contaminants & $204(44.3)$ & $51(37.0)$ \\
Fungi & $8(1.7)$ & $4(2.9)$ \\
Other & $5(1.1)$ & $3(2.2)$ \\
Total & 461 & 138
\end{tabular}

${ }^{\mathrm{a}}$ Common skin contaminants included: Bacillus sp., Corynebacterium sp., coagulase-negative Staphylococcus, Diphtheroids, Propionibacterium acnes, Propionibacterium propionicum, Propionibacterium sp. unspecified, Staphylococcus epidermidis, Staphylococcus auricularis, Staphylococcus capitis ssp. capitis, Staphylococcus capitis ssp. unspecified, Staphylococcus haemolyticus, Staphylococcus hominis, Staphylococcus lugdunensis, Staphylococcus simulans, Staphylococcus warneri, alpha-hemolytic Streptococcus, and Streptococcus viridans.

TABLE 3. Antimicrobial susceptibility among most frequently reported isolates ${ }^{a}$ from blood cultures reported by U.S. participants in outpatient dialysis surveillance, device-associated module, patient safety component, National Healthcare Safety Network, 2006

\begin{tabular}{lcc}
\hline & $\begin{array}{c}\text { Number of } \\
\text { isolates tested } \\
\text { and reported }\end{array}$ & $\begin{array}{c}\text { Number (\%) } \\
\text { resistant }\end{array}$ \\
\hline $\begin{array}{c}\text { Staphylococcus aureus } \\
\text { resistant to methicillin } \\
\begin{array}{c}\text { Enterococcus spp. resistant } \\
\text { to vancomycin }\end{array}\end{array}$ & 123 & $52(42 \%)$ \\
$\begin{array}{c}\text { Enterobacter spp. resistant } \\
\text { to third generation } \\
\text { cephalosporins }\end{array}$ & 17 & $10(26 \%)$ \\
\hline
\end{tabular}

${ }^{\mathrm{a}}$ The number of coagulase-negative staphylococci resistant to methicillin was $<5$ and omitted from the report.

enrollment information, please visit http:// www.cdc.gov/ncidod/dhqp/nhsn_FAQenrollment.html.

Dialysis centers interested in conducting surveillance for adverse events often ask about the time and resource investment surveillance activities require. A hospitalbased unit serving dialysis outpatients recently documented implementation of surveillance activities using the NHSN protocol (18). In their experience, the methods were easy to implement; maintenance of the activities required an estimated 2 hours of staff time per month. The facility observed that surveillance participation resulted in a decline in rates of bloodstream infections and antimicrobial use through ownership and engagement of staff (18).

The National Healthcare Safety Network provides tools for outpatient dialysis centers to analyze their own data so that they can monitor trends, evaluate needs for prevention, and measure the impact of their prevention efforts. Adjusting the number of events for patient risk factors, such as vascular access type, and the time period at risk is needed to compare rates across dialysis centers. The dialysis surveillance activities in the NHSN use patient-months as the adjustment for time at risk, but other methods are available and rates can be converted for comparability (19). For further information about surveillance and the prevention of dialysis-associated adverse events, please visit http://www.cdc.gov/ncidod/ dhqp/dpac_dialysis_pc.html.

\section{Disclaimer}

CDC Disclaimer: The findings and conclusions in this report are those of the authors and do not necessarily represent the views of the Centers for Disease Control and Prevention. Reprints are not available from the authors.

\section{Acknowledgment}

We are indebted to NHSN participants in dialysis surveillance for their ongoing efforts to monitor adverse events and improve patient safety.

\section{References}

1. NIH: U.S. Renal Data System, USRDS 2006 Annual Data Report. Bethesda, MD: National Institute of Diabetes and Digestive and Kidney Diseases, 2006

2. CDC: Recommendations for preventing transmission of infections among chronic hemodialysis patients. MMWR Recomm Rep 50(RR5): 1-43, 2001

3. Foundation NNK: Kidney Disease Outcomes Quality Initiative Clinical Practice Guidelines and Recommendations. http://www.kidney.org/pro fessionals/KDOQI/guideline upHD PD VA/index.htm. 2006

4. CDC: Guidelines for the prevention of intravascular catheter-related infections. MMWR Recomm Rep 51:1-28, 2002

5. Berns JS: Infection with antimicrobial-resistant microorganisms in dialysis patients. Semin Dial 16:30-37, 2003

6. Tokars JI, Finelli L, Alter MJ, Arduino MJ: National surveillance of dialysis-associated diseases in the United States, 2001. Semin Dial 17:310-319, 2004

7. CDC: National Nosocomial Infections Surveillance (NNIS) System Report, data summary from January 1992 through June 2004, issued October 2004. Am J Infect Control 32:470-485, 2004

8. Tokars JI: Description of a new surveillance system for bloodstream and vascular access infections in outpatient hemodialysis centers. Semin Dial 13:97-100, 2000

9. Edwards JR, Peterson KD, Andrus ML, Tolson JS, Goulding JS, Dudeck MA, Mincey RB, Pollock DA, Horan TC, The NHSN facilities: National Healthcare Safety Network (NHSN) Report, data summary for 2006, issued June 2007. Am J Infect Control 35:290-301, 2007

10. Klevens RM, Tokars JI, Andrus M: Electronic reporting of infections associated with hemodialysis. Nephrol News Issues 19:37-38, 2005

11. Stevenson KB, Adcox MJ, Mallea MC, Narasimhan N, Wagnild JP: Standardized surveillance of hemodialysis vascular access infections: 18-month experience at an outpatient, multifacility hemodialysis center. Infect Control Hosp Epidemiol 21:200-203, 2000

12. CMS. Fistula First. http://www.fistulafirst.org/partners.htm. 2004

13. Arduino MJ, Tokars JI: Why is an infection control program needed in the hemodialysis setting? Nephrol News Issues 19:44, 46-44 49, 2005

14. Tokars JI: Predictive value of blood cultures positive for coagulase-negative staphylococci: implications for patient care and health care quality assurance. Clin Infect Dis 39:333-341, 2004

15. Lamy B, Roy P, Carret G, Flandrois JP, Delignette-Muller ML: What is the relevance of obtaining multiple blood samples for culture? A comprehensive model to optimize the strategy for diagnosing bacteremia Clin Infect Dis 35:842-850, 2002

16. CDC: Invasive methicillin-resistant Staphylococcus aureus infections among dialysis patients - United States, 2005. MMWR Recomm Rep 56:197-199, 2007 
17. Siegel JDRE, Jackson M, Chiarello L, The Healthcare Infection Control Practices Advisory Committee: Management of multidrug-resistant organisms in healthcare settings, 2006. http://www.cdc.gov/ncidod/dhqp/ index.html. 2006.

18. George A, Tokars JI, Clutterbuck EJ, Bamford KB, Pusey C, Holmes $\mathrm{AH}$ : Reducing dialysis associated bacteraemia, and recommendations for surveillance in the United Kingdom: prospective study. $B M J$ 332:1435-1439, 2006

19. Tokars JI: Bloodstream infections in hemodialysis patients: getting some deserved attention. Infect Control Hosp Epidemiol 23:713-715, 2002 